\title{
An Empirical Study of Improved Kalecki Model Using China's Data
}

\author{
Xiaojing Zhang* \\ School of Finance, Harbin University of Commerce, Harbin 150028, China \\ book97@163.com
}

Keywords: FDI; Current account; Deficit; Investment return

\begin{abstract}
This paper uses China's data to do an empirical study to verify the improved Kalecki model which is presented by Xiaojing Zhang. It can be found that his investment return balance will decrease by 0.384189 percent when FDI increases by one percent; and it will increase by 0.314157 percent when IR increases by one percent. Thus, the conclusion of Kalecki Model is not correct as long as the host countries' investment returns overseas are greater than FDI' s investment profits and the improved Kalecki model is verified in a way.
\end{abstract}

\section{Introduction}

China's foreign exchange reserves decreased about 900 billion dollars in 2016, thus some economists are afraid of FDI' $s$ investment profits outflow might cause the current account deficit in the future.

Kalecki(1966)[1] studied the problem synthetically that FDI' s profits outflow could influence host countries' BOP equilibrium firstly. He argued that the deficit of BOP can not be avoided as long as the FDI' s net yield to their profits outflow ratio maintains a fixed rate.

A number of economists study the problem later and most of them have drawn similar conclusions to Kalecki [2-6]. Some other economists, however, have drawn their conclusions differrent with Kalecki[7-11]. Especially, Xiaojing Zhang(2015)[11] improved the Kalecki Model under the background of globalization and capital flow freely.

\section{The Improved Kalecki Model}

\section{Model Description.}

Xiaojing Zhang(2015) ${ }^{[11]}$ argued that it is necessary to pay more attention to the investment return overseas in BOP with the rapid development of international economic globalization and financial liberalization while analyzing FDI' s influence on the host countries current account, and then built an improved Kalecki model below.

Assuming that FDI' s investment profits is linearly related to FDI inflow, then the following linear regression equation can be obtained:

$$
R=\alpha+\beta \mathrm{FDI}+\gamma \mathrm{IR}+\varepsilon
$$

Where $\alpha, \beta, \gamma$ are estimated parameters, $\varepsilon$ is the disturbance.

According to the structure of BOP, the credit profits should be greater than the debit profits corresponding to equation(1) where FDI and inprofit happen to move counter and the absolute value of the latter should be greater than the former, namely the host countries should invest overseas and try to make the investment returns overseas greater than FDI' s investment profits while introducing FDI. If the host countries decide to introducing FDI, the income account mainly depends on its investment scale and returns overseas, see Fig.1. 


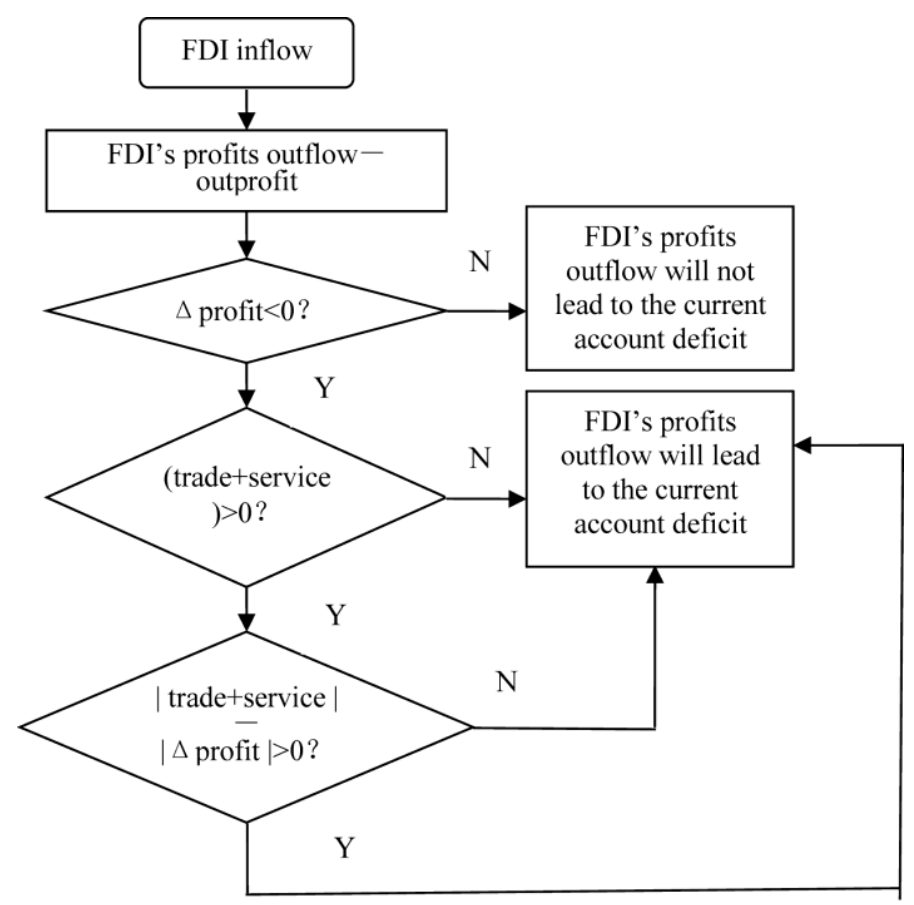

Figure 1 The flow chart of the relationship between FDI's investment profits outflow and the current account

\section{Empirical Study Using China's Data}

In order to verify the improved Kalecki model, we do an empirical study using China' s data. China' s FDI and investment return balance during 1982-2014, see table 1 and Fig. 2.

Table 1 China' s FDI and investment return balance during 1982-2014 (hundreds million dollars)

\begin{tabular}{|c|c|c|c|}
\hline Year & $\mathbf{R}$ & FDI & IR \\
\hline 1982 & 4 & 4 & 10 \\
\hline 1983 & 12 & 9 & 15 \\
\hline 1984 & 15 & 14 & 19 \\
\hline 1985 & 8 & 20 & 14 \\
\hline 1986 & 0 & 22 & 9 \\
\hline 1987 & -2 & 23 & 10 \\
\hline 1988 & -2 & 32 & 15 \\
\hline 1989 & 2 & 34 & 19 \\
\hline 1990 & 11 & 35 & 30 \\
\hline 1991 & 8 & 44 & 37 \\
\hline 1992 & 2 & 112 & 56 \\
\hline 1993 & -13 & 275 & 44 \\
\hline 1994 & -10 & 338 & 57 \\
\hline 1995 & -118 & 358 & 52 \\
\hline 1996 & -124 & 402 & 73 \\
\hline 1997 & -112 & 442 & 55 \\
\hline 1998 & -165 & 438 & 55 \\
\hline 1999 & -141 & 338 & 82 \\
\hline 2000 & -142 & 384 & 123 \\
\hline 2001 & -186 & 442 & 91 \\
\hline 2002 & -147 & 493 & 77 \\
\hline 2003 & -104 & 495 & 148 \\
\hline 2004 & -58 & 621 & 185 \\
\hline 2005 & -176 & 1041 & 359 \\
\hline 2006 & -71 & 1241 & 502 \\
\hline 2007 & 37 & 1562 & 766 \\
\hline 2008 & 222 & 1715 & 1027 \\
\hline 2009 & -157 & 1311 & 990 \\
\hline 2010 & -381 & 2437 & 1288 \\
\hline 2011 & -853 & 2801 & 1277 \\
\hline 2012 & -352 & 2412 & 1500 \\
\hline 2013 & -945 & 2909 & 1662 \\
\hline 2014 & -599 & 2891 & 1831 \\
\hline
\end{tabular}


Source: State Administration of Foreign Exchange. http://www.safe.gov.cn/wps/portal/sy/tjsj_szphb

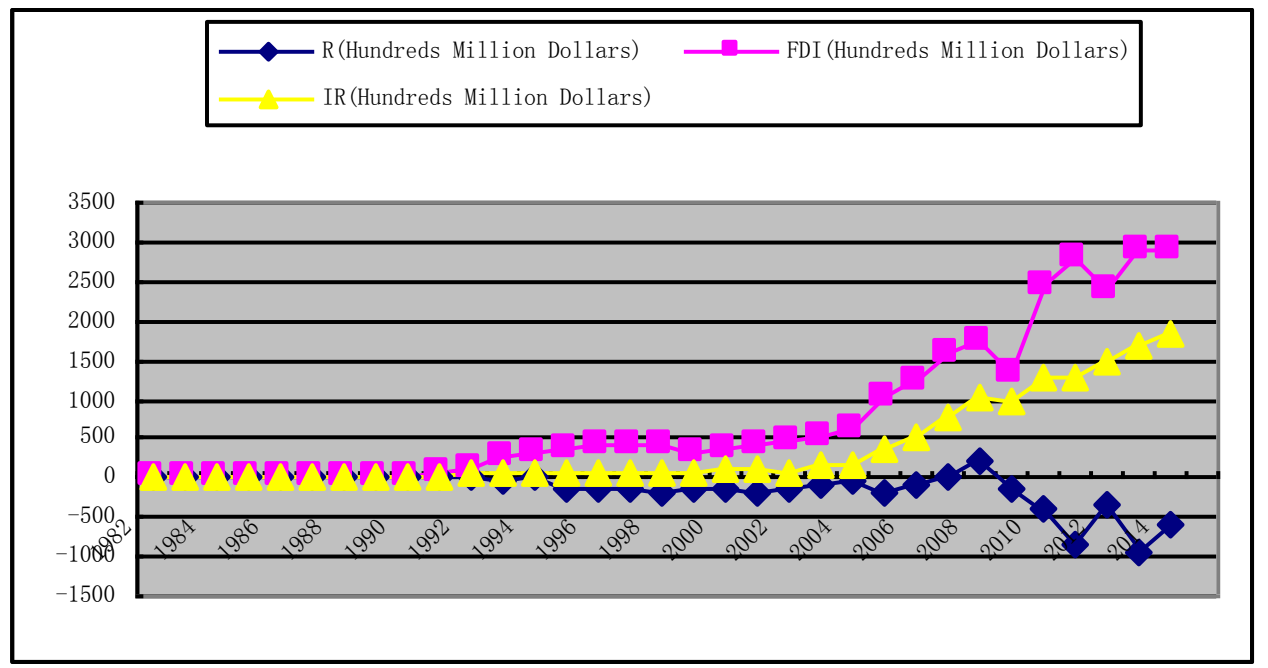

Figure 2. China's FDI and investment return balance during 1982-2014

The regression result of equation (1) see table 2.

Table 2 The regression result of equation (1)

\begin{tabular}{lllll}
\hline \hline Variable & Coefficient & Std. Error & t-Statistic & Prob. \\
\hline \hline FDI & -0.384189 & 0.132693 & -2.895320 & 0.0070 \\
$\boldsymbol{I R}$ & 0.314157 & 0.222809 & 1.409987 & 0.1688 \\
$\boldsymbol{C}$ & 42.86891 & 38.84048 & 1.103717 & 0.2785 \\
\hline \hline $\boldsymbol{R}$-squared & 0.626247 & Mean dependent var & -137.4848 \\
Adjusted $R$-squared & 0.601330 & S.D. dependent var & 244.7236 \\
S.E. of regression & 154.5192 & Akaike info criterion & 13.00502 \\
Sum squared resid & 716285.6 & Schwarz criterion & 13.14107 \\
Log likelihood & -211.5829 & F-statistic & 25.13346 \\
Durbin-Watson stat & 1.196413 & Prob(F-statistic) & 0.000000 \\
\hline \hline
\end{tabular}

$R=42.86891-0.384189 \mathrm{FDI}+0.314157 \mathrm{IR}$

\section{$(-2.895320) \quad(1.409987)$}

It can be found in table 2 that R2 is 0.626247 and t test of FDI under one percent significance has passed, $t$ test of IR under seventeen percent significance has passed. Equation (2) indicates that the investment return balance will decrease by 0.384189 percent when FDI increase by one percent; and it will increase by 0.314157 percent when IR increases by one percent.

Analysis of the Stocks of FDI Investment Returns.The stocks of FDI investment returns in China are 1701.4 billion dollars over the period of 1982-2014. At worst, assuming that the FDI investment returns remit intensively and made up by the trade plus, then it will need 51.18 percent of the stocks of trade plus 3324.4 billion dollars. However, it will only need 13.64 percent of the stocks of trade plus 3324.4 billion dollars since there are 1247.9 billion dollars of investment overseas returns in China which can be used to deal with the remittance of FDI investment returns directly.

During the 33 years of 1982-2014, the remittance of FDI investment returns didn' $t$ worsen China' s current account as what Kalecki described before. This shows that it played an important role in relieving the stress of the remittance of FDI investment returns with China' s continuing investing overseas and the returns increasing continuously from the reform and opening-up. Moreover, China's 
investment overseas returns accelerated to increase with its accession to WTO and it has kept pace with the growth of FDI investment returns in recent years, see table 3 and Fig.3. The deficit of the investment account will maintain in a low level and it can lay the first stone for the equilibrium of Balance of Payments as long as the momentum can be maintained in the long run, see Fig.4.

Table 3 China' s FDI and ODI investment return balance during 1982-2014 (hundreds million dollars)

\begin{tabular}{|c|c|c|}
\hline Year & OR & IR \\
\hline 1982 & 6 & 10 \\
\hline 1983 & 3 & 15 \\
\hline 1984 & 4 & 19 \\
\hline 1985 & 5 & 14 \\
\hline 1986 & 9 & 9 \\
\hline 1987 & 12 & 10 \\
\hline 1988 & 16 & 15 \\
\hline 1989 & 17 & 19 \\
\hline 1990 & 20 & 30 \\
\hline 1991 & 29 & 37 \\
\hline 1992 & 53 & 56 \\
\hline 1993 & 57 & 44 \\
\hline 1994 & 68 & 57 \\
\hline 1995 & 170 & 52 \\
\hline 1996 & 198 & 73 \\
\hline 1997 & 167 & 55 \\
\hline 1998 & 220 & 55 \\
\hline 1999 & 223 & 82 \\
\hline 2000 & 265 & 123 \\
\hline 2001 & 277 & 91 \\
\hline 2002 & 223 & 77 \\
\hline 2003 & 252 & 148 \\
\hline 2004 & 243 & 185 \\
\hline 2005 & 536 & 359 \\
\hline 2006 & 574 & 502 \\
\hline 2007 & 729 & 766 \\
\hline 2008 & 805 & 1027 \\
\hline 2009 & 1147 & 990 \\
\hline 2010 & 1669 & 1288 \\
\hline 2011 & 2130 & 1277 \\
\hline 2012 & 1851 & 1500 \\
\hline 2013 & 2607 & 1662 \\
\hline 2014 & 2429 & 1831 \\
\hline
\end{tabular}




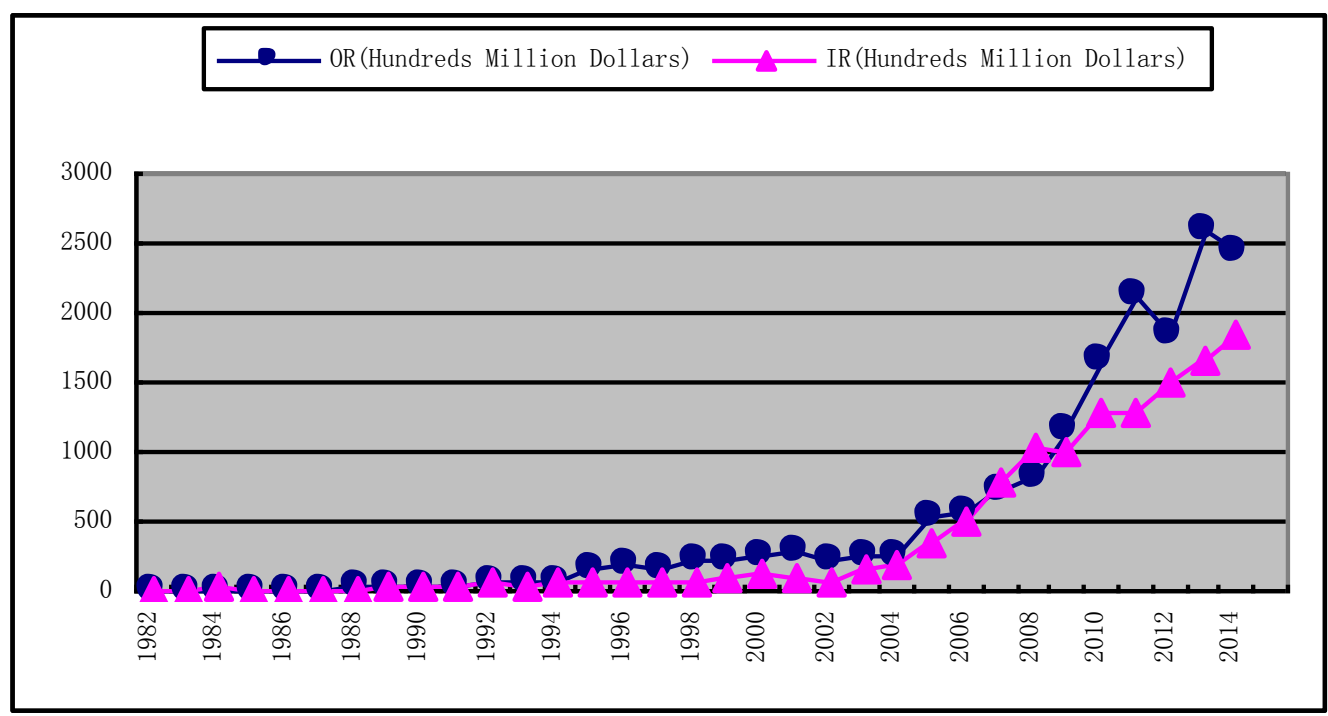

Figure 3. The changing trend of China's investment overseas profits and FDI' s investment profits during 1982-2014

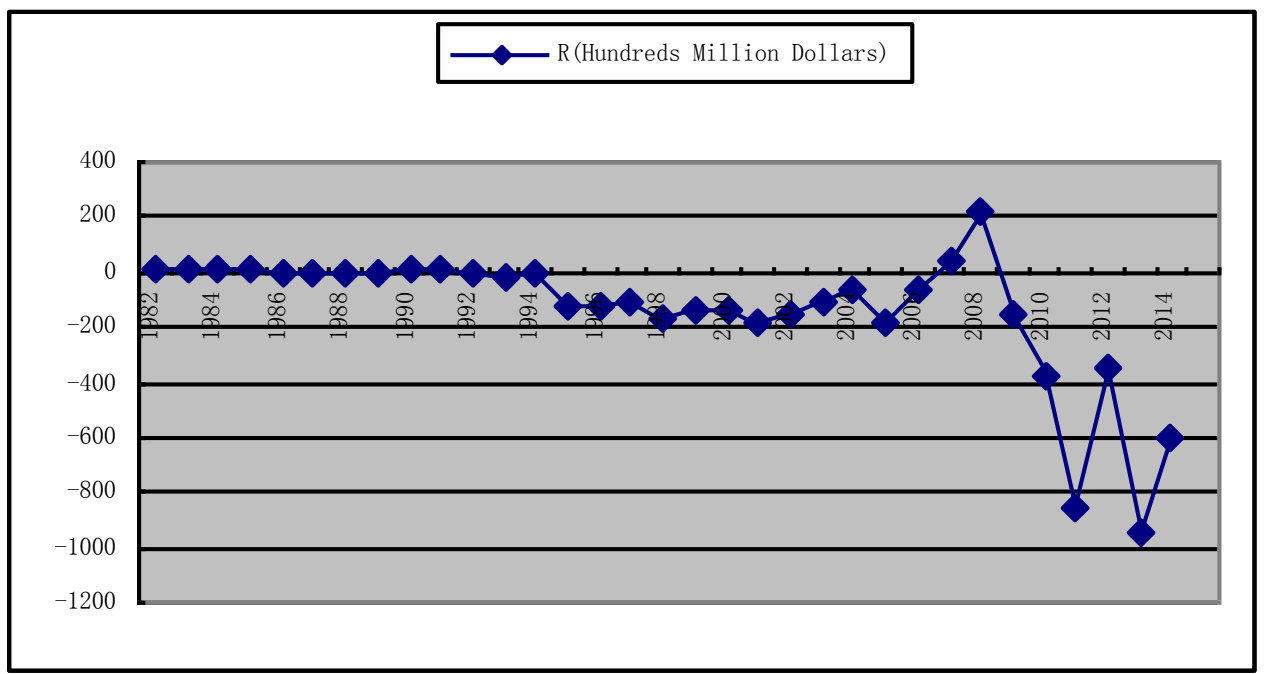

Figure 4. The changing trend of China's investment profits during 1982-2014

As analyzed above, FDI is negatively correlated to the investment balance and it will decrease by 0.384189 percent when FDI increase by one percent; on the contrary, the investment overseas returns is positively correlated to the investment balance and it will increase by 0.314157 percent when IR increases by one percent. Secondly, it can be found after analyzing the stocks of FDI investment returns, China' s investment overseas returns and the trade plus that China can deal with the intensive remittance of FDI investment returns by only using 13.64 percent of the trade plus since China has a large scale of stocks of investment overseas returns. The analysis shows that the investment overseas returns can play an important role in relieving the remittance stress of FDI investment returns. Thus, it can be China's basic state policy to encourage the enterprises invest overseas directly from the respective of policy significance.

It can be found that Kalecki provides a clear tread for researchers and policy makers in 1960' s when they explored the deficit effect of the remittance of FDI investment returns on the host countries, however, the suitability of his theory met challenge with the rapid development of globalization and finance liberalization in 1990' $\mathrm{s}$ and the BOP crises of host countries due to the remittance of FDI investment returns which was predicted by Kalecki didn' $t$ appear in some empirical studies.

This paper analyzes the limit of Kalecki theory which is based on the single direction of capital flow of the remittance of FDI investment returns, and find that the research conclusion of Kalecki model will be false as long as the investment overseas of the host countries are greater than FDI 
investment returns by building a regression model among the three variables - the balance of investment returns, FDI inflow and the investment overseas returns of the host countries. At the same time, this paper analyzes the compensation effect of other accounts and the equilibrium addition of the current account when the investment overseas returns of the host countries are less than FDI investment returns, accordingly improves Kalecki theory.

The research expands the analysis framework of current literatures by considering the factor of investment overseas returns of the host countries and it can truly reflect the return effect of the remittance of FDI investment returns on the host countries under the background of global capital flow.

\section{Conclusions}

In this paper, we use China' s data to do an empirical study to verify the improved Kalecki model. It can be found that he investment return balance will decrease by 0.384189 percent when FDI increase by one percent; and it will increase by 0.314157 percent when IR increase by one percent. Thus, the conclusion of Kalecki Model is not correct as long as the host countries' investment returns overseas is greater than FDI' s investment profits. Moreover, Kalecki theory is improved.

\section{Acknowledgements}

I really appreciate the support of the $\mathrm{PhD}$ Research Fund in Harbin University of Commerce (15RW18).

\section{References}

[1] Kalecki, Michal and Sachs I.. (1993) Forms of Foreign Aid: An Economic Analysis. Reprinted in Collected Works of Michal Kalecki. Vol. V. Developing economies. Trans. By Chester Adam Kisiel. Oxford: Clarendon Press.

[2] Woodward David. (2001) The Next Crisis? Direct and Equity Investment in Developing Countries. Zed Books: London.

[3] Yongding YU. (2003) Eliminate the phobophobia of Renminbi appreciation, realize the transition to economic smooth development. International Economic Review, 9-10: pp 5-11.

[4] Zhonggen MAO, Junshan DUAN. (2005) Theoretical and Empirical Analysis of FDI' s Investment Return Outflow and Balance of Payments Crisis. International Finance Research, 3: 45-51.

[5] Chul-Hwan Kim, and Donggeun Kim. (2011) Do capital inflows cause current account deficits? Applied Economics Letters, 18, pp 497-500.

[6] Shusong Ba. (2013) The impact of FDI' s profits evaluation and outflow on BOP. Economic forum, 8, 21-26.

[7] Gianpaolo Rossinia, and Paolo Zanghierib. (2009) Current account composition and sustainability of external debt. Applied Economics, 41, pp 677-683.

[8] M I Ansari, and A Ojemakinde. (2003) EXPLAINING ASYMMETRY IN THE U.S. MERCHANDISE AND SERVICE ACCOUNT BALANCE: Does the Service Sector Hold the Key to the U.S. Current Account Woes? THE INTERNATIONAL TRADE JOURNAL, Volume XVII, 1, pp 51-81.

[9] Yu Zhang, Jiazhi Xie. (2011) Empirical analysis of the effect of FDI on capital and financial account of China' s investment balance payments. Regional finance research, 12, pp 9-13.

[10] CEDRIC TILLE. (2008) Composition of International Assets and the Long-run Current Account. Economic Notes 3: Review of Banking, Finance and Monetary Economics, 37, pp 283-313.

[11] Xiaojing Zhang. (2015) Will FDI' s Investment Profits Outflow Cause the Current Account Deficit? The International Conference on Electronics, Mechanics, Culture and Medicine. Shenyang,China. 